\title{
The Influence of Moderate and High Dietary Long Chain Polyunsaturated Fatty Acids (LCPUFA) on Baboon Neonate Tissue Fatty Acids
}

\author{
ANDREA T. HSIEH, JOSHUA C. ANTHONY, DEBORAH A. DIERSEN-SCHADE, STEVEN C. RUMSEY, PETER LAWRENCE,
} CUN LI, PETER W. NATHANIELSZ, AND J. THOMAS BRENNA

Division of Nutritional Sciences [A.T.H., P.L., J.T.B.], Cornell University, Ithaca, New York 14853; Mead Johnson and Company [J.C.A., D.A.D.-S., S.C.R.], Evansville, Indiana 47721; Center for Pregnancy and Newborn Research [C.L., P.W.N.], University of Texas Health Science Center San Antonio, San Antonio, Texas 78229

\begin{abstract}
Docosahexaenoic acid (DHA) and arachidonic acid (ARA) are now common ingredients in commercial infant formulas, however, the optimal levels have not been established. Our previous data showed that the current amount of DHA in U.S. term formulas, $0.3 \% \mathrm{w} / \mathrm{w}$, is insufficient to normalize cerebral cortex DHA to levels in breastfed baboon neonate controls (Diau et al:: BMC Medicine 3: 11, 2005). Here, we report on the influence of higher formula DHA levels on 12-wk-old full-term baboon CNS and visceral organs. Fourteen nursery-reared baboons were randomized to one of three diets: control (C, no DHA-ARA); moderate LCPUFA (L, $0.33 \%$ DHA-0.67\% ARA); high LCPUFA (L3, $1.00 \%$ DHA$0.67 \%$ ARA). DHA increased significantly in liver, heart, and plasma (all $\mathrm{C}<\mathrm{L}<\mathrm{L} 3), \mathrm{RBC}(\mathrm{C}<\mathrm{L}, \mathrm{L} 3)$, and $\mathrm{CNS}$ regions: precentral gyrus $(\mathrm{C}<\mathrm{L}<\mathrm{L} 3)$, frontal cortex, inferior and superior colliculi, globus pallidus, and caudate (all $\mathrm{C}<\mathrm{L}$, L3). These data extend previous observations indicating that 1) tissue DHA is more sensitive to diet than ARA; 2) cerebral cortex DHA increases with higher levels of DHA than in present commercial formulas; and 3) basal ganglia and limbic system DHA saturate with levels of DHA currently available in formulas. These results imply that higher levels of DHA are necessary to normalize cortex DHA to those found in breastfed animals. (Pediatr Res 61: 537-545, 2007)
\end{abstract}

$\mathrm{D}$ HA (22:6n-3) and ARA (20:4n-6) are ingredients specifically added to many infant formulas worldwide. Studies of DHA and ARA as formula components have focused on infant functions closely associated with neural tissue normally high in DHA, specifically visual acuity $(1,2)$ and retinal $(3,4)$ and cognitive function (5). ARA's importance is associated with insuring normal growth, and, for this specific outcome, present target levels in formula of about $0.6 \%(\mathrm{w} / \mathrm{w})$ of FA appear to be effective (6). ARA may also enhance the function of DHA (7), though data on this point are fewer than for DHA alone.

Before 1995, infant formulas worldwide were devoid of LCPUFA. U.S. infant formulas have contained DHA and ARA since 2002, and about $80 \%$ of the formulas consumed in

Received November 13, 2006; accepted January 9, 2007.

Correspondence: J. Thomas Brenna, Cornell University, Savage Hall, Ithaca, NY 14853; e-mail: jtb4@cornell.edu

This work was supported by Mead-Johnson Nutritionals, Evansville, IN, and National Institutes of Health training grant (DK07158).

DOI: $10.1203 /$ pdr.0b013e318045bec9 the United States contain DHA/ARA at this writing. However, the amount of DHA and ARA required for optimal development is not well characterized. Experimental infant formulas range over at least 6 -fold in human and primate studies $(8,9)$, and presently vary by more than 2 -fold in commercial U.S. infant formulas. In 2001, a group of clinical researchers recommended a minimum of $0.20 \%(\mathrm{w} / \mathrm{w})$ DHA and $0.35 \%$ (w/w) ARA (10), corresponding roughly to about $19 \mathrm{mg}$ DHA/100 kcal and $21 \mathrm{mg}$ ARA/100 kcal. However, 11 studies of healthy term infants considered in a comprehensive systematic review in 2000 used levels from 0.10 to $0.36 \%(w / w)$ (11). Benefits to term infants of higher DHA levels cannot be ruled out because they have not been investigated.

Intake of DHA above $0.36 \%$ may impart benefits not observed at present levels. Worldwide breastmilk has a median level of about $0.32 \%(\mathrm{w} / \mathrm{w})$, but ranges to more than $1 \%$ (12); for instance, it averaged $1.4 \%$ for the Inuit women of northern Canada, who have a diet high in marine mammals (13). These levels of n-3 LCPUFA are well known to have bioactivities associated with cardiovascular function, including effects on blood lipids, that are not observed at low intakes (14). Beyond these human compositional data, one primate study of $1.0 \%$ DHA formula showed improved neuromotor development in 1-mo-old rhesus monkey neonates compared with controls consuming no LCPUFA (9).

The CNS has long been known to be rich in DHA and ARA, and for this reason has been a major target for DHA studies. Work in our laboratory has demonstrated that DHA $(0.30 \%)$ and ARA $(0.55 \%)$ supplementation to $4 \mathrm{wk}$ of age in neonatal baboons increases DHA throughout the CNS, but ARA is largely unaffected (15). Those data further showed that DHA levels of supplemented neonates were similar in most CNS

\footnotetext{
Abbreviations: AdrA, adrenic acid (22:4n-6); ARA, arachidonic acid (20:4n-6); BW, body weight; C, control formula: DHA $(0 \% \mathrm{w} / \mathrm{w})$, ARA (0\%w/w); DHA, docosahexaenoic acid (22:6n-3); DPAn-3, 7,10,13,16,19docosapentaenoic acid (22:5n-3); DPAn-6, 4,7,10,13,16-docosapentaenoic acid (22:5n-6); EPA, eicosapentaenoic acid (20:5n-3); FA, fatty acid; L, LCPUFA moderate formula: DHA $(0.33 \%)$, ARA (0.67\%); L3, LCPUFA high formula: DHA (1.00\%), ARA (0.67\%); LCPUFA, $(\geq 20$ carbons) longchain polyunsaturated fatty acids; RBC, red blood cells; SFA, saturated fatty acids; w/w, weight ratio of FA to total FA
} 
regions (basal ganglia, limbic system, hippocampus, amygdala, thalamus, midbrain) to those of a randomized breastfed group. Importantly, all sampled regions of gray matter of the cerebral cortex and cerebellum were lower in supplemented animals than in cortex of breastfed animals. The cerebral cortex and cerebellum contain more than half the DHA in the $\mathrm{CNS}$, and thus it is reasonable to expect that smaller regions such as the basal ganglia might be less susceptible to DHA insufficiency.

Our purpose here is to report on the changes in tissue FA composition that accompany increased levels of DHA, with emphasis on the CNS. The DHA level in the high DHA formula was chosen to correspond to the higher end of human breastmilk DHA (12); the ARA content was the same in both LCPUFA formulas because the $0.64 \%$ ARA level of commercial formula is already above the median worldwide ARA level, and to test whether higher formula DHA has an influence on tissue ARA. This study was conducted in neonatal baboons who, in the wild, are omnivorous primates with lipid metabolism similar to that of humans (16). An LCPUFA-free formula control was compared with LCPUFA formulas supplemented at two different levels in a randomized controlled study.

\section{METHODS}

Animals. All animal work took place at the Southwest Foundation for Biomedical Research (SFBR) located in San Antonio, TX. Animal protocols were approved by the SFBR and Cornell University Institutional Animal Care and Use Committee (IACUC). Animal characteristics are summarized in Table 1. Fourteen pregnant baboons delivered spontaneously around $182 \mathrm{~d}$ gestation. Neonates were transferred to the nursery within $24 \mathrm{~h}$ of birth and randomized to one of three diet groups. Animals were housed in enclosed incubators until 2 wk of age and then moved to individual stainless steel cages in a controlled access nursery. Room temperatures were maintained at $76-82^{\circ} \mathrm{F}$, with a 12 -h light/dark cycle. They were fed on experimental formulas until $12 \mathrm{wk}$ of life, compared with 4 or 6 wk of feeding in our previous studies $(15,17)$.

Diets. Animals were assigned to one of the three experimental formulas, with LCPUFA concentrations presented in Table 2. Target concentrations were set as shown in brackets and diets were formulated with excess to account for analytical and manufacturing variability and/or possible losses during storage. Control (C) and L, moderate DHA formula, are the commercially available human infant formulas Enfamil

Table 1. Characteristics of baboon neonate groups (mean $\pm S D$ )

\begin{tabular}{lccc}
\hline \multicolumn{1}{c}{ Diet group } & $\mathrm{C}$ & $\mathrm{L}$ & $\mathrm{L} 3$ \\
\hline $\begin{array}{l}\text { Number of } \\
\text { animals }(n)\end{array}$ & 5 & 4 & 5 \\
$\begin{array}{l}\text { Gender } \\
\text { Conceptional age at }\end{array}$ & $181.3 \pm 4.5$ & $179.7 \pm 10.1$ & $183.4 \pm 5.2$ \\
$\quad$ delivery $(\mathrm{d})$ & & & \\
Birth weight $(\mathrm{g})$ & $801.4 \pm 120.5$ & $900.5 \pm 132.0$ & $887.0 \pm 198.6$ \\
$\quad$ Weight at $12 \mathrm{wk}(\mathrm{g})$ & $1473.2 \pm 248.2$ & $1510.3 \pm 261.9$ & $1572 \pm 370.0$ \\
Weight gain $(\mathrm{g})$ & $671.8 \pm 192.4$ & $609.8 \pm 141.4$ & $685 \pm 249.7$ \\
\hline
\end{tabular}

Table 2. Formula LCPUFA composition

\begin{tabular}{llll}
\hline & $\mathrm{C}$ & \multicolumn{1}{c}{$\mathrm{L}$} & \multicolumn{1}{c}{$\mathrm{L} 3$} \\
\hline & & & \\
DHA $(\%, \mathrm{w} / \mathrm{w})$ & 0 & $0.42 \pm 0.02[0.33]$ & $1.13 \pm 0.04[1.00]$ \\
$(\mathrm{mg} / 100 \mathrm{kcal})$ & & $21.3 \pm 1.0[17]$ & $62.8 \pm 1.9[51]$ \\
ARA $(\%, \mathrm{w} / \mathrm{w})$ & 0 & $0.77 \pm 0.02[0.67]$ & $0.71 \pm 0.01[0.67]$ \\
$(\mathrm{mg} / 100 \mathrm{kcal})$ & & $39.4 \pm 0.9[34]$ & $39.2 \pm 0.7[34]$ \\
\hline
\end{tabular}

Bracketed values are target concentrations; as-analyzed concentrations $($ mean $\pm \mathrm{SD})$ are higher as noted in the text.

and Enfamil LIPIL, respectively. Formula L3 had an equivalent concentration of ARA and was targeted at 3-fold the concentration of DHA.

Formulas were kindly provided by Mead Johnson \& Company (Evansville, IN) in ready-to-feed form. Each diet was sealed in cans assigned two different color-codes to mask investigators. Animals were offered 1 ounce of formula four times daily at $0700,1000,1300$, and $1600 \mathrm{~h}$ with an additional feed during the first two nights. On d 3 and beyond, neonates were offered 4 ounces total; when they consumed the entire amount, the amount offered was increased in daily 2-ounce increments. Neonates were hand fed for the first 7-10 d until independent feeding was established.

Growth. Neonatal growth was assessed using body weight measurements, recorded two or three times weekly. Head circumference and crown-rump length data were obtained weekly for each animal. Organ weights were recorded at necropsy at $12 \mathrm{wk}$.

Sampling. Animals were anesthetized, and euthanized by exsanguination at $84.57 \pm 1.09 \mathrm{~d}$. Blood was collected in EDTA-containing Vacutainer tubes, and RBC and plasma were separated by centrifugation. Eyes and one brain hemisphere were removed and immediately dissected. CNS structures were dissected by an experienced neurologist, weighed, flash frozen in liquid nitrogen, and stored at $-80^{\circ} \mathrm{C}$ until they were analyzed in their entirety. Retina and 1-g samples of left ventricle and right liver lobe were removed and treated similarly.

Analyses. Total lipids were extracted from tissue homogenates using the Bligh and Dyer method (18). Fatty acid methyl esters (FAME) were prepared using sodium hydroxide and $14 \%$ boron-trifluoride $\left(\mathrm{BF}_{3}\right)$ in methanol, and were analyzed by gas chromatography (HP 5890; BPX-70 column, SGE, Austin, TX), using $\mathrm{H}_{2}$ carrier gas as described previously (17). FA identities were determined by covalent adduct chemical ionization tandem mass spectrometry (19) and then quantified using methyl heptadecanoate as an internal standard and response factors derived from an equal weight FAME mixture. FA concentrations are expressed as percentage weight of total FA from 14 to 24 carbons.

Statistics. Data are expressed as mean \pm SD. Statistical analysis was conducted using ANOVA to test the hypothesis of equivalent means for measures taken at $12 \mathrm{wk}$, and Tukey's correction was used to control for multiple comparisons. Formula consumption, body weight, head circumference, and crown-rump length changes over time were tested with a random coefficient regression model to compare LCPUFA 
groups (L, L3) to control (C). Analysis were performed using SAS for Windows 9.1 (SAS Institute, Cary, NC) with significance declared at $p<0.05$.

\section{RESULTS}

Growth. Figure $1 A$ shows formula consumption throughout the $12 \mathrm{wk}$; there were no significant differences between LCPUFA groups and the $\mathrm{C}$ group over time $(p=0.64)$. Similarly, no significant changes over time were found for body weight ( $\mathrm{BW}, p=0.47)$, head circumference ( $p=0.68$ ), crown-rump length $(\mathrm{CRL}, p=0.38)$, or the ratio $\mathrm{BW} / \mathrm{CRL}$ $(p>0.50)$ (data not presented). Figure $1 B$ shows there were no significant differences in the 12 -wk data for these anthropometry measures. Figure $1 C$ shows that there were no significant differences and no trends in the 12-wk organ weights, expressed as a percentage of body weight (BW), for brain, liver, thymus, spleen, heart, lungs, the right kidney, or the pancreas.
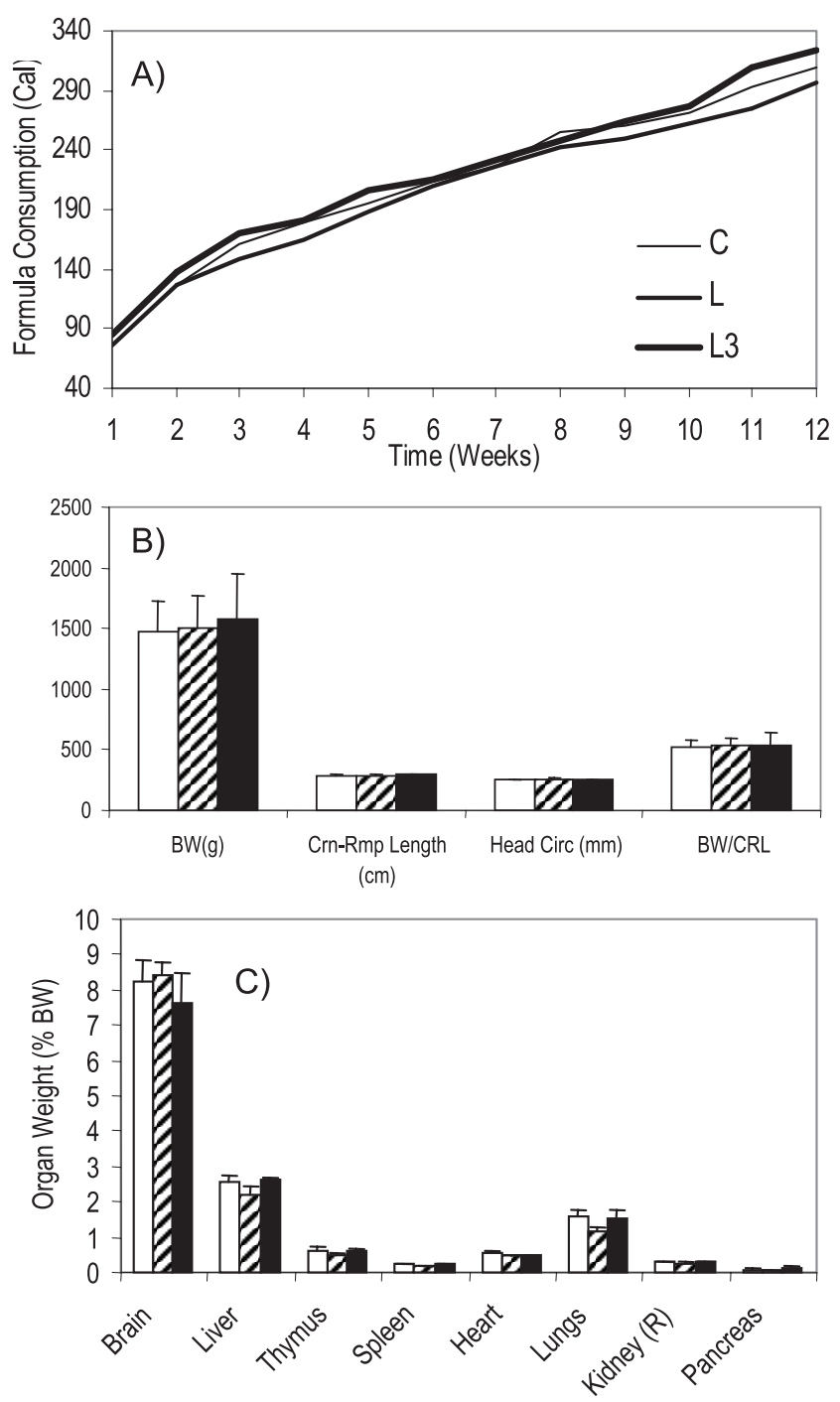

Figure 1. Formula consumption and growth. (A) Formula consumption (cal/d), (B) $12 \mathrm{wk}$ anthropometry, and $(C)$ organ weights $(\% \mathrm{BW})$ at $12 \mathrm{wk}$. There were no significant differences among the groups. C: open bars; L: hatched bars; L3: solid bars.
Liver and heart FA. FA composition of whole liver is presented in Table 3, and results for DHA, ARA, and the DPAn-6/DHA ratio, a measure of n-3 FA sufficiency, are shown graphically in Figure 2. Increasing formula DHA significantly elevated liver DHA concentrations; the L and L3 groups had 2.2- and 3.6-fold more DHA than the C group, respectively. In contrast to DHA, dietary ARA increased liver levels in L group; ARA dropped $14.3 \%$ from the L to L3 group. The concentrations of the ARA elongation product, adrenic acid (AdrA), were significantly higher in the $\mathrm{C}$ group $(0.99 \pm 0.13 \%)$ relative to $\mathrm{L}$ and L3. A similar, but nonsignificant trend was observed for DPAn-6; levels were highest in $\mathrm{C}$ animals, followed by the L and L3 groups. DPAn-3 concentrations dropped 2-fold for LCPUFA animals compared with controls. DPAn-6/DHA was significantly elevated for the $\mathrm{C}$ and $\mathrm{L}$ groups, compared with L3, by 4.6- and 14-fold. Increases in LCPUFA were compensated by decreases in total monounsaturated fatty acids (MUFA) and linoleic acid (LA, 18:2n-6), but not total saturated fatty acids (SFA).

As with the liver, heart DHA increased in the L and L3 groups, 2.8- and 3.9-fold, respectively, while DPAn-3 dropped significantly. The increases in DHA appear to be at the expense of SFA, though the decrease in SFA from $C$ to $L$ to L3 did not reach statistical significance. Linoleic acid decreased from $\mathrm{C}$ to $\mathrm{L}$ but $\mathrm{L}$ and $\mathrm{L} 3$ were not different.

$\boldsymbol{R B C}$ and plasma $\boldsymbol{F A}$. Table 3 also summarizes FA profiles for RBC and for whole plasma. Supplementation significantly elevated RBC DHA for L and L3 groups by 3.8- and 4.6-fold, compared with controls. A similar trend was observed in plasma, DHA increased by 4.6- and 7.5-fold for the LCPUFAsupplemented groups, L and L3. Whereas ARA significantly increased from $\mathrm{C}$ to $\mathrm{L}$ for $\mathrm{RBC}$, ARA levels declined from the $\mathrm{L}$ to the L3 group. A consistent but nonsignificant trend is present for ARA plasma concentrations, with a moderate increase from $\mathrm{C}(5.36 \pm 1.00)$ to $\mathrm{L}(10.06 \pm 0.99)$ and an intermediate level in L3 (7.79 \pm 0.84$)$. AdrA is a minor component but did respond to diets in both $\mathrm{RBC}$ and plasma, where it decreased significantly in the L3 group compared with the $\mathrm{C}$ and L groups. DPAn-6 concentrations were significantly higher in RBC of controls. DPAn-3 levels were higher in the $\mathrm{C}$ group compared with the $\mathrm{L}$ and $\mathrm{L} 3$ groups in both RBC and plasma measurements. The DPAn-6/DHA ratio was significantly greater for control and L animals compared with the L3 group, approximately by 4 - and 10 -fold.

Retina FA. Table 4 and Figure 2 depict retinal FA composition. Changes in retinal DHA due to dietary LCPUFA did not reach significance, though the $\mathrm{L}$ and L3 group means were greater than the $\mathrm{C}$ group by amounts similar to our previous report (4). ARA concentrations were not influenced by formula composition. DPAn-6 concentrations were significantly higher in controls compared with the highest supplemented group, L3. Levels of DPAn-3 increased with dietary LCPUFA, with L3 significantly elevated compared with the C group. The DPAn-6/DHA index for $\mathrm{C}$ and $\mathrm{L}$ groups were 3.6-fold higher than the high DHA formula group, L3.

CNS FA. CNS FA concentrations are summarized in Tables 4-6 and Figure 2. DHA concentrations significantly increased 
Table 3. Liver, RBC, plasma, and heart FA composition $(\%, w / w ;$ mean $\pm S D)$

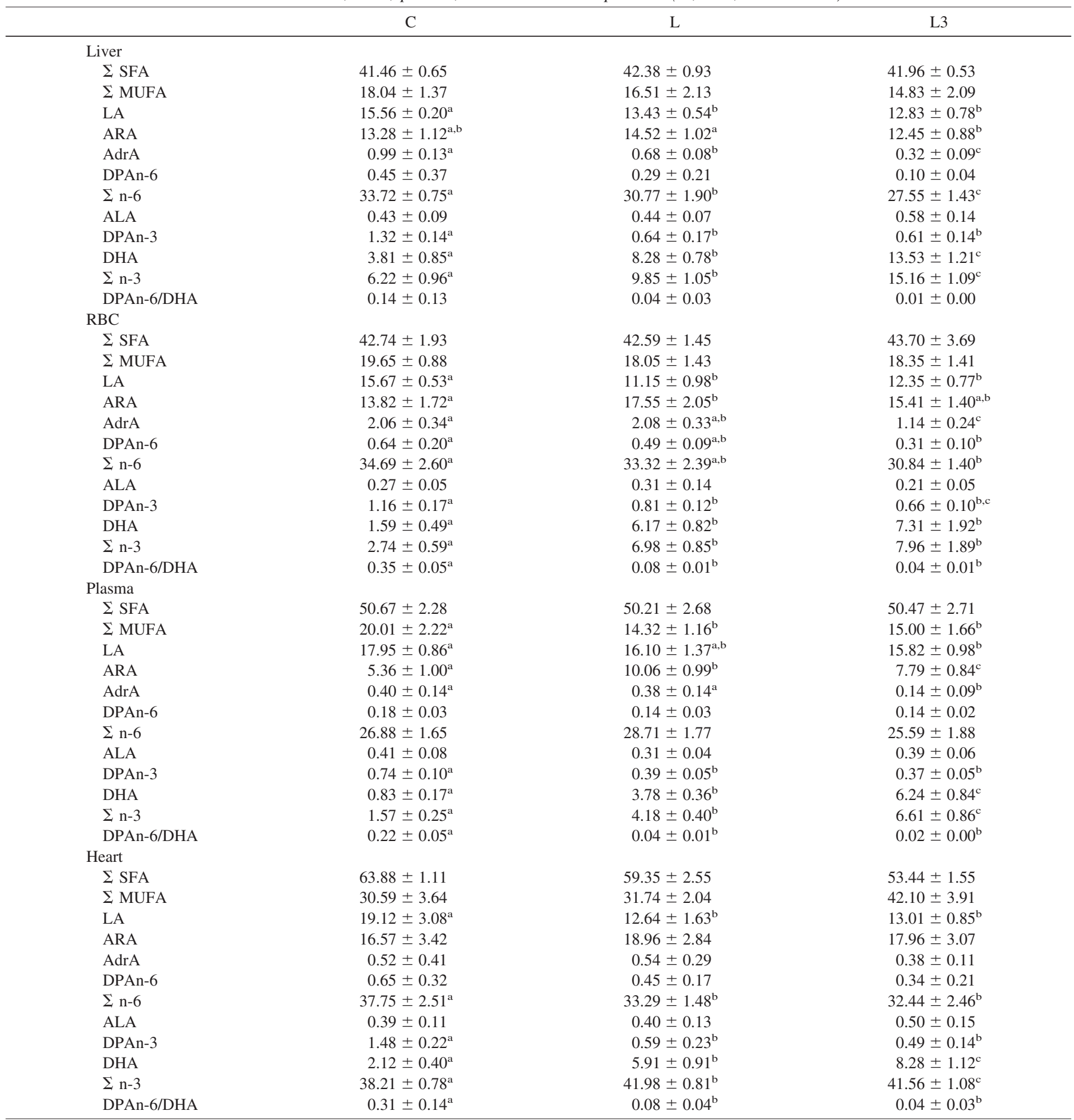

Different superscripts within a line designate differences between groups $(p<0.05)$.

with higher levels of formula DHA in the cerebral cortex precentral gyrus, the primary motor cortex region. Supplementation improved DHA levels by $24 \%$ and $43 \%$ compared with controls in the L and L3 groups, respectively, and the difference between L and L3 was statistically significant. LCPUFA supplementation also significantly increased DHA in frontal cortex by $30 \%$ and $41 \%$ in the L and L3 groups, respectively, compared with controls, however the difference between L and L3 was borderline significant $(p=0.10)$.
Formula DHA increased DHA in the basal ganglia regions globus pallidus and caudate, and in the midbrain regions superior colliculus and inferior colliculus, however, there were no detectable differences between $\mathrm{L}$ and $\mathrm{L} 3$ groups. The nonsignificant trends in putamen and amygdala were consistent with this pattern. DPAn-6 decreased significantly and consistently from $\mathrm{C}$ to $\mathrm{L}$ to $\mathrm{L} 3$ in all CNS regions.

With the exception of two CNS regions, dietary manipulation had little influence on ARA levels. Levels of ARA in globus pallidus and superior colliculus were highest in the $\mathrm{L}$ 


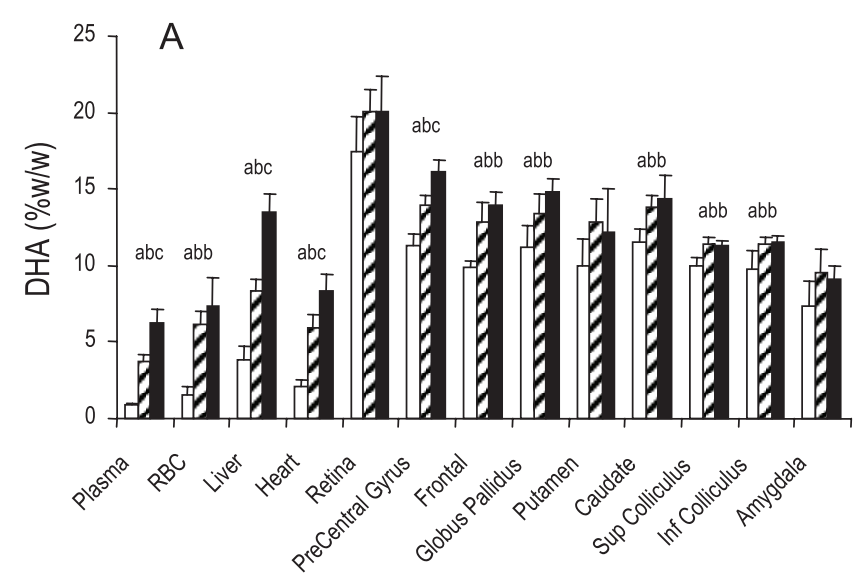

closely, with correlation coefficients ranging for RBC from 0.86 to 0.99 , and for total plasma FA from 0.96 to 0.99 ; CNS coefficients were from 0.94 to 0.99 . Regression slopes for liver were 1.49 (RBC) and 1.78 (plasma), indicating that the liver concentrates DHA compared with these blood pools. Heart DHA coefficients were close to $1(1.01,1.14)$, indicating that, on average, heart total FA closely track these two pools. CNS slopes ranged from 0.59 to 0.71 , indicating that the CNS is less responsive to dietary DHA than liver and heart. CNS intercepts were near 10 (DHA, \%w/w), whereas liver and heart were between 0.39 and 2.1 .

\section{DISCUSSION}
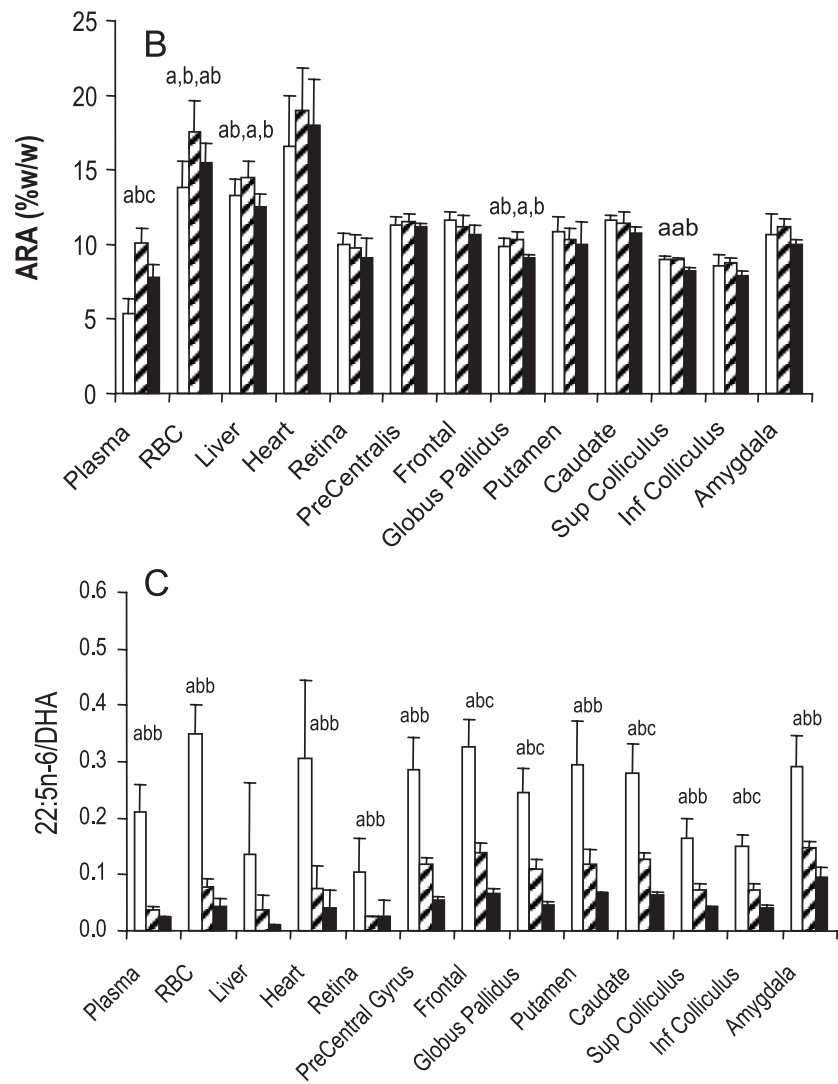

Figure 2. Selected baboon neonate FA concentrations at $12 \mathrm{wk}$ of age. (A) DHA, $(B)$ ARA, and $(C)$ [DPAn-6]/[DHA] ratio. Different superscripts within a tissue designate differences between groups $(p<0.05)$. C: open bars; L: hatched bars; L3: solid bars.

formula group, but significantly declined $10 \%$ with additional formula DHA.

Similar results for $\mathrm{n}-3$ sufficiency indices were obtained in all brain regions. The DPAn-6/DHA ratio was significantly elevated for $\mathrm{C}$ compared with the high formula DHA group, $\mathrm{L} 3$, in all CNS regions. The L and L3 groups were significantly different in frontal lobe, globus pallidus, caudate, and inferior colliculus. $\mathrm{C}$ and $\mathrm{L}$ groups were consistently elevated by 2- to 5-fold, respectively, compared with the L3 group.

Figure 3 presents results of regression analysis of mean DHA in blood pools and the four tissues that showed significant increases in DHA in the L3 group, plus the frontal lobe. Mean RBC and plasma DHA levels tracked mean tissue DHA

Previous studies of n-3 deficiency in infant rhesus monkeys have shown impaired retinal function (20). The reduction in tissue DHA in the deficiency state is completely reversed upon high DHA/ eicosapentaenoic acid (20:5n-3; EPA) feeding (21), however, a recent study shows that deficiency during pregnancy is fully reversed, with $18: 3 n-3$ feeding postnatally in cerebral cortex but not in retina (22). Similar complete reversal of n-3 deficiency symptoms was achieved for combined 18:3n-3/DHA re-feeding of n-3 deficient rats, including recovery of performance in the Morris water maze (23). The mechanism of impaired visual response has been traced to rod recovery rather than phototransduction compared with responses for retinas of animals fed diets with either 18:3n-3 at $8 \%, \mathrm{w} / \mathrm{w}$ or DHA at $0.6 \%, \mathrm{w} / \mathrm{w}$ of FA (24). These studies show that dietary supply of precursor or preformed DHA is essential for normal function, and that specific neural tissues can show differential responses to dietary FA.

We have published several studies on tissue compositional changes that accompany DHA and ARA dietary supplementation in perinatal baboons $(15,17,25-27)$. The present data are in most cases consistent with our previous findings and extend them to formulas with higher levels of DHA. Increasing DHA from $0(\mathrm{C})$ to $0.33 \%$ (L) increases DHA in all tissues studied, consistent with previous observations in 4-wk-old baboons (15), though the increases in retina, putamen, and amygdala did not reach statistical significance in the present study.

We previously showed that the response of individual CNS regions to dietary DHA was dichotomous. Dietary DHA at $0.3 \%$, w/w normalized tissue DHA to levels found in breastfed neonates for all regions of the CNS except for the lobes of the cerebral cortex, where DHA increased compared with controls but was $87-90 \%$ of breastfed levels (15). A reasonable hypothesis is that higher DHA levels might further increase cortex DHA to breastfed levels. Our present data show that precentral gyrus DHA increased by $24 \%$ from C to $\mathrm{L}$, and $43 \%$ from $\mathrm{C}$ to $\mathrm{L} 3$. The additional increase from $\mathrm{L}$ to L3 of 19\% was statistically significant, indicating that the greater DHA in the L3 formula was effective at increasing precentral gyrus DHA. Although we did not have a breastfed control group in this study, the magnitude of the increase is similar to the enhancement associated with the breastfed versus term comparison. We note also that the magnitude of the precentral gyrus DHA increase was less than 2-fold, whereas the amount of DHA in the diet is triple between $\mathrm{L}$ and 
Table 4. Retina, cerebral cortex precentral gyrus and frontal lobe FA compositions (\%, w/w; mean \pm SD)

\begin{tabular}{|c|c|c|c|}
\hline & $\mathrm{C}$ & $\mathrm{L}$ & L3 \\
\hline \multicolumn{4}{|c|}{ Cerebral cortex, precentral gyrus } \\
\hline$\Sigma \mathrm{SFA}$ & $45.83 \pm 1.05$ & $46.09 \pm 1.00$ & $45.03 \pm 0.32$ \\
\hline$\sum$ MUFA & $17.90 \pm 0.52$ & $17.22 \pm 0.46$ & $17.71 \pm 0.45$ \\
\hline ARA & $11.32 \pm 0.52$ & $11.49 \pm 0.53$ & $11.19 \pm 0.18$ \\
\hline AdrA & $6.15 \pm 0.51^{\mathrm{a}}$ & $6.02 \pm 0.21^{\mathrm{a}, \mathrm{b}}$ & $5.39 \pm 0.37^{\mathrm{b}}$ \\
\hline DPAn-6 & $3.21 \pm 0.52^{\mathrm{a}}$ & $1.64 \pm 0.24^{\mathrm{b}}$ & $0.88 \pm 0.07^{\mathrm{c}}$ \\
\hline DHA & $11.27 \pm 0.78^{\mathrm{a}}$ & $13.97 \pm 0.66^{\mathrm{b}}$ & $16.11 \pm 0.73^{\mathrm{c}}$ \\
\hline$\sum n-3$ & $11.82 \pm 0.73^{\mathrm{a}}$ & $14.39 \pm 0.50^{\mathrm{b}}$ & $16.57 \pm 0.72^{\mathrm{c}}$ \\
\hline DPAn-6/DHA & $0.29 \pm 0.06^{\mathrm{a}}$ & $0.12 \pm 0.01^{\mathrm{b}}$ & $0.05 \pm 0.01^{\mathrm{b}}$ \\
\hline \multicolumn{4}{|c|}{ Cerebral cortex, frontal lobe } \\
\hline$\Sigma$ SFA & $44.33 \pm 0.74$ & $44.30 \pm 0.67$ & $42.96 \pm 2.98$ \\
\hline$\Sigma$ MUFA & $15.48 \pm 1.31$ & $16.04 \pm 0.62$ & $16.38 \pm 1.06$ \\
\hline$\sum n-6$ & $14.14 \pm 0.61^{\mathrm{a}}$ & $11.15 \pm 0.23^{\mathrm{b}}$ & $10.96 \pm 1.75^{\mathrm{b}, \mathrm{c}}$ \\
\hline DPAn-3 & $0.53 \pm 0.04^{\mathrm{a}}$ & $0.32 \pm 0.01^{\mathrm{b}}$ & $0.42 \pm 0.04^{\mathrm{c}}$ \\
\hline DHA & $9.86 \pm 0.42^{\mathrm{a}}$ & $12.80 \pm 1.30^{\mathrm{b}}$ & $13.89 \pm 0.95^{\mathrm{b}}$ \\
\hline$\Sigma n-3$ & $10.39 \pm 0.40^{\mathrm{a}}$ & $13.12 \pm 1.30^{\mathrm{b}}$ & $14.31 \pm 0.96^{\mathrm{b}}$ \\
\hline DPAn-6/DHA & $0.33 \pm 0.05^{\mathrm{a}}$ & $0.14 \pm 0.02^{\mathrm{b}}$ & $0.07 \pm 0.01^{\mathrm{c}}$ \\
\hline \multicolumn{4}{|l|}{ Retina } \\
\hline$\Sigma$ SFA & $45.61 \pm 0.81$ & $46.41 \pm 3.08$ & $46.68 \pm 3.37$ \\
\hline$\Sigma$ MUFA & $16.63 \pm 0.49$ & $15.57 \pm 0.50$ & $15.87 \pm 0.88$ \\
\hline LA & $2.78 \pm 0.21$ & $2.63 \pm 0.29$ & $2.39 \pm 0.20$ \\
\hline ARA & $9.99 \pm 0.76$ & $9.76 \pm 0.88$ & $9.09 \pm 1.37$ \\
\hline AdrA & $1.89 \pm 0.49$ & $1.34 \pm 0.17$ & $1.25 \pm 0.38$ \\
\hline DPAn-6 & $1.82 \pm 0.96^{\mathrm{a}}$ & $0.51 \pm 0.03^{\mathrm{a}, \mathrm{b}}$ & $0.55 \pm 0.48^{\mathrm{b}}$ \\
\hline
\end{tabular}

Different superscripts within a line designate differences between groups $(p<0.05)$.

L3. This observation indicates that the leveling off of tissue FA concentrations in response to increases in dietary FA, demonstrated in rats (28), is achieved in the primate brain at dietary DHA levels similar to the highest reported breastmilk levels.

The basal ganglia are a set of CNS organs that integrate and coordinate signals from the frontal cortex associated with executive function and motor coordination. The superior colliculus is a brainstem structure that controls saccades and also has cortical inputs, and the inferior colliculus is associated with the localization of sounds (29). Collectively, these CNS regions showed no significant difference in DHA between the L and L3 groups. In only the globus pallidus was the nonsignificant difference in L and L3 DHA of potential biologic importance (11\%); in the other tissues, DHA increased by less than $4 \%$ or decreased slightly. In part from this observation, we infer that the necessarily modest statistical power of this primate study did not limit our ability to detect differences. Together with our previous study (15), these results are consistent with the conclusion that the cerebral cortex DHA is most sensitive to modest dietary DHA levels. Considering that DHA in the human CNS increases through $2 \mathrm{y}$ of life (30), and that the cerebral cortex is quantitatively the largest CNS region, DHA demands may be important well beyond infancy.

Human (12) and baboon breastmilks (31) contain the n-3 LCPUFA EPA and DPA at concentrations that are a substantive fraction of the DHA concentration. In adult humans, these LCPUFA are much more efficiently converted to DHA than $\alpha$-linolenic acid (ALA, 18:3n-3) (32). U.S. infant formulas contain negligible amounts of EPA and n-3 DPA because the source of n-3 LCPUFA, oil from the marine algae Crypthecodinium cohnii, does not contain these LCPUFA. DHA levels higher than in formulas currently, and more similar to our L3 formula, may be indicated to make up for these minor n-3 LCPUFA. Indeed, we find that n-3 DPA drops in most tissue in response to moderate DHA but rebounds at the L3 DHA level. The exception is retina in which n-3 DPA increases as DHA increases. EPA is at trace levels in the CNS.

In liver, $\mathrm{RBC}$, and plasma, ARA rises significantly in the $\mathrm{L}$ group and then achieves an intermediate value in the L3 group; an equivalent but nonsignificant pattern was found for heart. Our present results are consistent with previous data (15) indicating that tissue ARA concentrations, particularly in 
Table 5. Basal ganglia (globus pallidus, putamen, caudate) and amygdala (\%,w/w; mean \pm SD)

\begin{tabular}{|c|c|c|c|}
\hline & $\mathrm{C}$ & $\mathrm{L}$ & L3 \\
\hline \multicolumn{4}{|l|}{ Globus pallidus } \\
\hline$\Sigma$ SFA & $40.83 \pm 0.42$ & $41.89 \pm 0.95$ & $40.74 \pm 0.71$ \\
\hline$\Sigma$ MUFA & $18.38 \pm 1.11$ & $17.46 \pm 0.56$ & $18.65 \pm 0.82$ \\
\hline ARA & $9.84 \pm 0.61^{\mathrm{a}, \mathrm{b}}$ & $10.26 \pm 0.63^{\mathrm{a}}$ & $9.14 \pm 0.19^{\mathrm{b}}$ \\
\hline AdrA & $5.90 \pm 0.29^{\mathrm{a}}$ & $5.64 \pm 0.25^{\mathrm{a}, \mathrm{b}}$ & $5.18 \pm 0.24^{\mathrm{b}}$ \\
\hline DPAn-6 & $2.71 \pm 0.27^{\mathrm{a}}$ & $1.44 \pm 0.21^{\mathrm{b}}$ & $0.70 \pm 0.07^{\mathrm{c}}$ \\
\hline DHA & $11.19 \pm 1.41^{\mathrm{a}}$ & $13.39 \pm 1.26^{\mathrm{b}}$ & $14.82 \pm 0.83^{\mathrm{b}}$ \\
\hline$\sum n-3$ & $11.61 \pm 1.32^{\mathrm{a}}$ & $13.66 \pm 1.24^{\mathrm{a}, \mathrm{b}}$ & $15.21 \pm 0.86^{\mathrm{b}}$ \\
\hline DPAn-6/DHA & $0.25 \pm 0.04^{\mathrm{a}}$ & $0.11 \pm 0.02^{\mathrm{b}}$ & $0.05 \pm 0.01^{\mathrm{c}}$ \\
\hline \multicolumn{4}{|l|}{ Putamen } \\
\hline$\Sigma$ SFA & $44.38 \pm 1.59$ & $43.71 \pm 2.29$ & $43.96 \pm 2.83$ \\
\hline$\Sigma$ MUFA & $17.60 \pm 1.36$ & $17.23 \pm 0.78$ & $18.31 \pm 3.39$ \\
\hline$\sum n-6$ & $22.59 \pm 1.89^{\mathrm{a}}$ & $19.97 \pm 1.07^{\mathrm{b}}$ & $18.87 \pm 0.99^{\mathrm{b}}$ \\
\hline DPAn-3 & $0.44 \pm 0.06^{\mathrm{a}}$ & $0.28 \pm 0.03^{\mathrm{b}}$ & $0.42 \pm 0.07^{\mathrm{a}, \mathrm{c}}$ \\
\hline DHA* & $10.03 \pm 1.71$ & $12.84 \pm 1.55$ & $12.19 \pm 2.88$ \\
\hline$\Sigma \mathrm{n}-3$ & $10.47 \pm 1.68$ & $13.12 \pm 1.52$ & $12.61 \pm 2.83$ \\
\hline DPAn-6/DHA & $0.29 \pm 0.08^{\mathrm{a}}$ & $0.12 \pm 0.02^{\mathrm{b}}$ & $0.07 \pm 0.00^{\mathrm{b}}$ \\
\hline \multicolumn{4}{|l|}{ Caudate } \\
\hline$\Sigma$ SFA & $42.95 \pm 0.87$ & $43.18 \pm 1.50$ & $43.10 \pm 0.61$ \\
\hline$\Sigma$ MUFA & $15.70 \pm 0.42$ & $15.79 \pm 0.83$ & $17.02 \pm 1.13$ \\
\hline LA & $1.11 \pm 0.08$ & $1.00 \pm 0.10$ & $1.03 \pm 0.06$ \\
\hline ARA & $11.64 \pm 0.30$ & $11.40 \pm 0.79$ & $10.77 \pm 0.38$ \\
\hline AdrA & $6.41 \pm 0.32^{\mathrm{a}}$ & $6.14 \pm 0.39^{\mathrm{a}, \mathrm{b}}$ & $5.74 \pm 0.32^{\mathrm{b}}$ \\
\hline DPAn-6 & $3.17 \pm 0.36^{\mathrm{a}}$ & $1.74 \pm 0.12^{\mathrm{b}}$ & $0.90 \pm 0.05^{\mathrm{c}}$ \\
\hline LA & $1.00 \pm 0.09$ & $0.86 \pm 0.06$ & $0.97 \pm 0.16$ \\
\hline ARA & $10.67 \pm 1.36$ & $11.23 \pm 0.52$ & $10.01 \pm 0.35$ \\
\hline AdrA & $5.60 \pm 0.79$ & $5.92 \pm 0.84$ & $5.07 \pm 1.10$ \\
\hline DPAn-6 & $2.08 \pm 0.21^{\mathrm{a}}$ & $1.41 \pm 0.22^{\mathrm{b}}$ & $0.85 \pm 0.08^{c}$ \\
\hline$\sum n-6$ & $20.82 \pm 1.93$ & $20.59 \pm 1.44$ & $18.28 \pm 1.35$ \\
\hline DPAn-3 & $0.35 \pm 0.03^{\mathrm{a}}$ & $0.28 \pm 0.01^{\mathrm{b}}$ & $0.41 \pm 0.03^{\mathrm{c}}$ \\
\hline DHA & $7.36 \pm 1.59$ & $9.55 \pm 1.57$ & $9.09 \pm 0.93$ \\
\hline$\sum n-3$ & $7.71 \pm 1.61$ & $9.84 \pm 1.57$ & $9.50 \pm 0.95$ \\
\hline DPAn-6/DHA & $0.29 \pm 0.06^{\mathrm{a}}$ & $0.15 \pm 0.01^{\mathrm{b}}$ & $0.09 \pm 0.02^{\mathrm{b}}$ \\
\hline
\end{tabular}

Different superscripts within a line designate differences between groups $(p<0.05)$.

* Multiple comparison $p=0.08$; L vs C, $p<0.04$.

the CNS are more refractory to formula ARA than DHA. No changes were found in the cerebral cortex, retina, putamen, caudate, and amygdala. However, L3 group ARA was reduced compared with control in the superior colliculus and compared with $\mathrm{L}$ in the globus pallidus. When a difference in ARA concentrations was evident, our previous data usually showed that tissue ARA was lower in groups consuming no ARA compared with a breastfed group (15).

n-6 DPA (Osbond acid) is an elongation and 4-5 desaturation product of ARA that consistently rises in experimental n-3 FA deficiency (33), and also drops in response to DHA supplementation in otherwise normal primates (17). n-6 DPA dropped in all tissues with increasing DHA, and in some tissues such as the cerebral cortex, L3 n-3 DPA values were a fraction of the $\mathrm{C}$ values. This decrease and the accompanying increase in DHA drove the DPA/DHA ratio decrease from the $\mathrm{L}$ to $\mathrm{L} 3$ groups. We have previously shown that DPA replacement with DHA results in improved retinal function directly in premature neonate baboons (4), and dietary supply of DHA has been linked to improved retinal function in numerous human infant studies (1). Cognition also improves in response to DHA and ARA supplementation (5). Whether increased DHA results in measurable enhancement of function awaits studies directly in humans. 
Table 6. Superior and inferior colliculi FA composition $(\%, w / w ;$ mean $\pm S D)$

\begin{tabular}{|c|c|c|c|}
\hline & $\mathrm{C}$ & $\mathrm{L}$ & L3 \\
\hline \multicolumn{4}{|l|}{ Superior colliculus } \\
\hline$\Sigma$ SFA & $39.17 \pm 3.01$ & $39.91 \pm 3.72$ & $37.88 \pm 1.08$ \\
\hline$\Sigma$ MUFA & $22.56 \pm 0.72$ & $22.40 \pm 0.80$ & $23.39 \pm 0.35$ \\
\hline ARA & $8.95 \pm 0.28^{\mathrm{a}}$ & $8.96 \pm 0.19^{\mathrm{a}}$ & $8.22 \pm 0.22^{\mathrm{b}}$ \\
\hline AdrA & $6.28 \pm 0.17^{\mathrm{a}}$ & $6.01 \pm 0.28^{\mathrm{a}, \mathrm{b}}$ & $5.70 \pm 0.36^{\mathrm{b}}$ \\
\hline DPAn-6 & $1.65 \pm 0.34^{\mathrm{a}}$ & $0.84 \pm 0.11^{\mathrm{b}}$ & $0.48 \pm 0.02^{\mathrm{b}, \mathrm{c}}$ \\
\hline DHA & $10.01 \pm 0.56^{\mathrm{a}}$ & $11.36 \pm 0.51^{\mathrm{b}}$ & $11.27 \pm 0.34^{\mathrm{b}}$ \\
\hline$\sum n-3$ & $10.38 \pm 0.54^{\mathrm{a}}$ & $11.71 \pm 0.54^{\mathrm{b}}$ & $11.77 \pm 0.35^{\mathrm{b}}$ \\
\hline DPAn-6/DHA & $0.16 \pm 0.03^{\mathrm{a}}$ & $0.07 \pm 0.01^{\mathrm{b}}$ & $0.04 \pm 0.00^{\mathrm{b}}$ \\
\hline \multicolumn{4}{|l|}{ Inferior colliculus } \\
\hline$\Sigma$ SFA & $39.52 \pm 3.49$ & $40.52 \pm 3.07$ & $37.85 \pm 1.49$ \\
\hline$\Sigma$ MUFA & $23.20 \pm 0.91^{\mathrm{a}, \mathrm{b}}$ & $22.70 \pm 0.79^{\mathrm{a}}$ & $24.07 \pm 0.47^{\mathrm{b}}$ \\
\hline$\sum n-6$ & $18.98 \pm 0.67^{\mathrm{a}}$ & $17.86 \pm 0.28^{\mathrm{b}}$ & $16.60 \pm 0.59^{c}$ \\
\hline DPAn-3 & $0.46 \pm 0.13^{\mathrm{a}, \mathrm{b}}$ & $0.35 \pm 0.05^{\mathrm{a}}$ & $0.54 \pm 0.07^{\mathrm{b}}$ \\
\hline DHA & $9.81 \pm 1.16^{\mathrm{a}}$ & $11.38 \pm 0.52^{\mathrm{b}}$ & $11.49 \pm 0.48^{\mathrm{b}}$ \\
\hline$\sum n-3$ & $10.26 \pm 1.09^{\mathrm{a}}$ & $11.72 \pm 0.53^{\mathrm{b}}$ & $12.03 \pm 0.53^{\mathrm{b}}$ \\
\hline DPAn-6/DHA & $0.15 \pm 0.02^{\mathrm{a}}$ & $0.07 \pm 0.01^{\mathrm{b}}$ & $0.04 \pm 0.00^{c}$ \\
\hline
\end{tabular}

Different superscripts within a line designate differences between groups $(p<0.05)$.
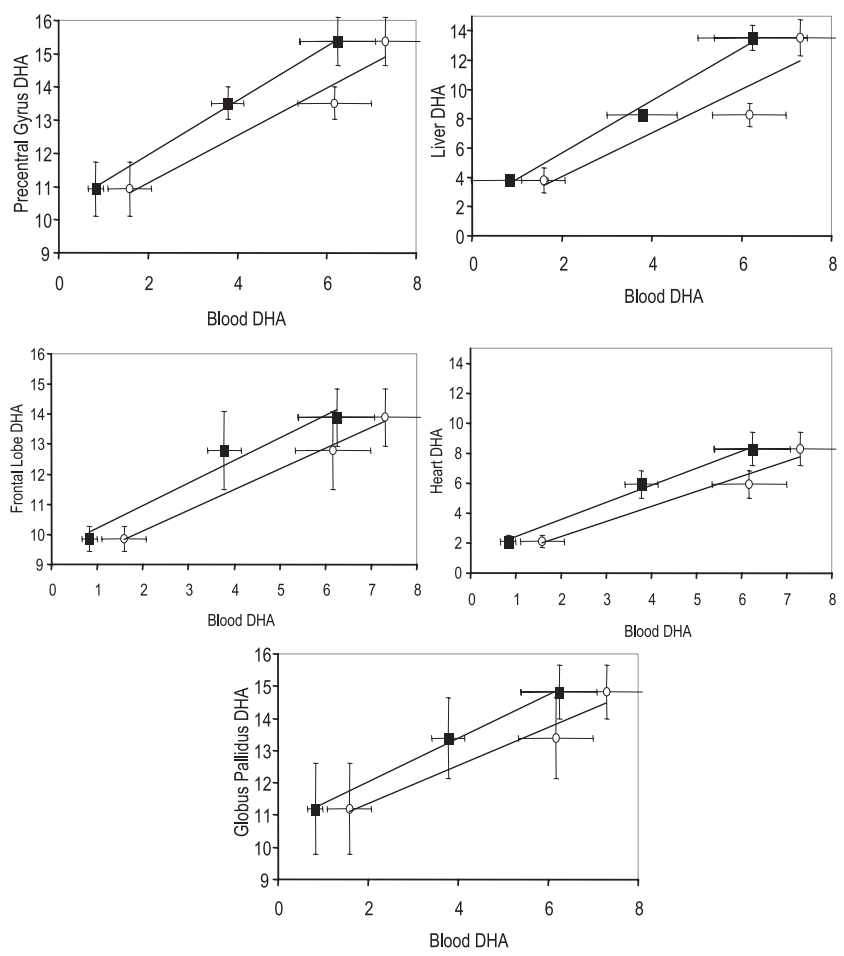

Figure 3. Tissue and plasma $(\square)$ or RBC $(\bigcirc)$ correlations. Four tissues plus frontal lobe showed significantly increased DHA between the L and L3 groups. Regression equations and correlation coefficients calculated using means are as follows. R: RBC; P: plasma. Precentral gyrus (PG): PG = $0.71 \mathrm{R}+9.7\left(r^{2}=0.94\right) ; \mathrm{PG}=0.82 \mathrm{P}+10.3\left(r^{2}=0.99\right) ;$ frontal lobe $(\mathrm{F}):$ $\mathrm{F}=0.69 \mathrm{R}+8.7\left(r^{2}=0.99\right) ; \mathrm{F}=0.75 \mathrm{P}+9.5\left(r^{2}=0.96\right)$; globus pallidus $(\mathrm{G}): \mathrm{G}=0.59 \mathrm{R}+10.2\left(r^{2}=0.96\right), \mathrm{G}=0.67 \mathrm{P}+10.7\left(r^{2}=0.99\right)$; liver $(\mathrm{L}): \mathrm{L}=1.49 \mathrm{R}+1.1\left(r^{2}=0.86\right), \mathrm{L}=1.78 \mathrm{P}+2.1\left(r^{2}=0.99\right)$; heart $(\mathrm{H})$ : $\mathrm{H}=1.01 \mathrm{R}+0.39\left(r^{2}=0.96\right), \mathrm{H}=1.14 \mathrm{P}+1.31\left(r^{2}=0.99\right)$.
In summary, these results confirm previous observations indicating that DHA is more sensitive to dietary manipulations than ARA in most tissues. They extend our previous conclusions by showing that cerebral cortex DHA increases with higher concentrations of DHA than are included in present commercial infant formulas, while not increasing the levels of DHA in basal ganglia and limbic system. These increases in DHA status were accompanied by normal growth; we present data elsewhere showing that clinical panels and hematology (Hsieh et al., 2007, unpublished observations) were all within normal ranges and raised no concerns over the safety of formula DHA levels studied here.

The data also provide support for the hypothesis that formula DHA at concentrations higher than presently used in formulas, but nevertheless well within the known range of human breastmilk, normalizes CNS tissue composition closer to that of breastfeeding. Changes in tissue composition by themselves do not justify alteration of diet composition, and should be coupled to demonstrations of efficacy associated with improvements in functional outcomes. The enhanced DHA in the primary motor cortex (precentral gyrus) may help explain enhanced motor maturity seen in one month old rhesus neonates fed a similar level of DHA (9), and a correlation of plasma phospholipid DHA with gross motor developmental quotient in 4-mo-old human infants (34). Studies of enhanced motor function linked to DHA consumption in humans are warranted.

\section{REFERENCES}

1. Morale SE, Hoffman DR, Castaneda YS, Wheaton DH, Burns RA, Birch EE 2005 Duration of long-chain polyunsaturated fatty acids availability in the diet and visual acuity. Early Hum Dev 81:197-203 
2. Birch EE, Castaneda YS, Wheaton DH, Birch DG, Uauy RD, Hoffman DR 2005 Visual maturation of term infants fed long-chain polyunsaturated fatty acidsupplemented or control formula for 12 mo. Am J Clin Nutr 81:871-879

3. Jeffrey BG, Weisinger HS, Neuringer M, Mitchell DC 2001 The role of docosahexaenoic acid in retinal function. Lipids 36:859-871

4. Diau GY, Loew ER, Wijendran V, Sarkadi-Nagy E, Nathanielsz PW, Brenna JT 2003 Docosahexaenoic and arachidonic acid influence on preterm baboon retinal composition and function. Invest Ophthalmol Vis Sci 44:4559-4566

5. Willatts P, Forsyth JS 2000 The role of long-chain polyunsaturated fatty acids in infant cognitive development. Prostaglandins Leukot Essent Fatty Acids 63:95-100

6. Clandinin MT, Van Aerde JE, Merkel KL, Harris CL, Springer MA, Hansen JW, Diersen-Schade DA 2005 Growth and development of preterm infants fed infant formulas containing docosahexaenoic acid and arachidonic acid. J Pediatr 146:461-468

7. Birch EE, Garfield S, Hoffman DR, Uauy R, Birch DG 2000 A randomized controlled trial of early dietary supply of long-chain polyunsaturated fatty acids and mental development in term infants. Dev Med Child Neurol 42:174-181

8. Gibson RA, Chen W, Makrides M 2001 Randomized trials with polyunsaturated fatty acid interventions in preterm and term infants: functional and clinical outcomes. Lipids 36:873-883

9. Champoux M, Hibbeln JR, Shannon C, Majchrzak S, Suomi SJ, Salem NJr., Higley JD 2002 Fatty acid formula supplementation and neuromotor development in rhesus monkey neonates. Pediatr Res 51:273-281

10. Koletzko B, Agostoni C, Carlson SE, Clandinin T, Hornstra G, Neuringer M, Uauy R, Yamashiro Y, Willatts P 2001 Long chain polyunsaturated fatty acids (LC-PUFA) and perinatal development. Acta Paediatr 90:460-464

11. SanGiovanni JP, Berkey CS, Dwyer JT, Colditz GA 2000 Dietary essential fatty acids, long-chain polyunsaturated fatty acids, and visual resolution acuity in healthy fullterm infants: a systematic review. Early Hum Dev 57:165-188

12. Lauritzen L, Hansen HS, Jorgensen MH, Michaelsen KF 2001 The essentiality of long chain n-3 fatty acids in relation to development and function of the brain and retina. Prog Lipid Res 40:1-94

13. Innis SM, Kuhnlein HV 1988 Long-chain n-3 fatty acids in breast milk of Inuit women consuming traditional foods. Early Hum Dev 18:185-189

14. Dewailly E, Blanchet C, Lemieux S, Sauve L, Gingras S, Ayotte P, Holub BJ 2001 n-3 Fatty acids and cardiovascular disease risk factors among the Inuit of Nunavik. Am J Clin Nutr 74:464-473

15. Diau GY, Hsieh AT, Sarkadi-Nagy EA, Wijendran V, Nathanielsz PW, Brenna JT 2005 The influence of long chain polyunsaturate supplementation on docosahexaenoic acid and arachidonic acid in baboon neonate central nervous system. BMC Med 3:11

16. Kushwaha RS, McGill HC Jr 1998 Diet, plasma lipoproteins and experimental atherosclerosis in baboons (Papio sp.). Hum Reprod Update 4:420-429.

17. Sarkadi-Nagy E, Wijendran V, Diau GY, Chao AC, Hsieh AT, Turpeinen A, Nathanielsz PW, Brenna JT 2003 The influence of prematurity and long chain polyunsaturate supplementation in 4-week adjusted age baboon neonate brain and related tissues. Pediatr Res 54:244-252

18. Bligh EG, Dyer WJ 1959 A rapid method of total lipid extraction and purification. Can J Biochem Physiol 37:911-917
19. Van Pelt CK, Brenna JT 1999 Acetonitrile chemical ionization tandem mass spectrometry to locate double bonds in polyunsaturated fatty acid methyl esters. Anal Chem 71:1981-1989

20. Neuringer M, Connor WE, Van Petten C, Barstad L 1984 Dietary omega-3 fatty acid deficiency and visual loss in infant rhesus monkeys. J Clin Invest 73:272-276

21. Connor WE, Neuringer M, Lin DS 1990 Dietary effects on brain fatty acid composition: the reversibility of n-3 fatty acid deficiency and turnover of docosahexaenoic acid in the brain, erythrocytes, and plasma of rhesus monkeys. J Lipid Res 31:237-247

22. Anderson GJ, Neuringer M, Lin DS, Connor WE 2005 Can prenatal N-3 fatty acid deficiency be completely reversed after birth? Effects on retinal and brain biochemistry and visual function in rhesus monkeys. Pediatr Res 58:865-872

23. Moriguchi T, Salem NJ 2003 Recovery of brain docosahexaenoate leads to recovery of spatial task performance. J Neurochem 87:297-309

24. Jeffrey BG, Mitchell DC, Gibson RA, Neuringer M 2002 n-3 fatty acid deficiency alters recovery of the rod photoresponse in rhesus monkeys. Invest Ophthalmol Vis Sci 43:2806-2814

25. Su HM, Bernardo L, Mirmiran M, Ma XH, Corso TN, Nathanielsz PW, Brenna JT 1999 Bioequivalence of dietary alpha-linolenic and docosahexaenoic acids as sources of docosahexaenoate accretion in brain and associated organs of neonatal baboons. Pediatr Res 45:87-93

26. Su HM, Corso TN, Nathanielsz PW, Brenna JT 1999 Linoleic acid kinetics and conversion to arachidonic acid in the pregnant and fetal baboon. J Lipid Res 40:1304-1312

27. Su HM, Huang MC, Saad NM, Nathanielsz PW, Brenna JT 2001 Fetal baboons convert 18:3n-3 to 22:6n-3 in vivo. A stable isotope tracer study. J Lipid Res 42:581-586

28. Lands WE, Morris A, Libelt B 1990 Quantitative effects of dietary polyunsaturated fats on the composition of fatty acids in rat tissues. Lipids 25:505-516

29. Kandel ER, Schwartz JH, Jessell TM 2000 Principles of Neuroscience. McGrawHill, New York

30. Martinez M 1992 Tissue levels of polyunsaturated fatty acids during early human development. J Pediatr 120:S129-S138

31. Sarkadi-Nagy E, Wijendran V, Diau GY, Chao AC, Hsieh AT, Turpeinen A, Lawrence P, Nathanielsz PW, Brenna JT 2004 Formula feeding potentiates docosahexaenoic and arachidonic acid biosynthesis in term and preterm baboon neonates. J Lipid Res 45:71-80

32. Pawlosky RJ, Hibbeln JR, Novotny JA, Salem N Jr, 2001 Physiological compartmental analysis of alpha-linolenic acid metabolism in adult humans. J Lipid Res 42:1257-1265

33. Salem N Jr, Loewke J, Catalan JN, Majchrzak S, Moriguchi T 2005 Incomplete replacement of docosahexaenoic acid by n- 6 docosapentaenoic acid in the rat retina after an n-3 fatty acid deficient diet. Exp Eye Res 81:655-663

34. Voigt RG, Jensen CL, Fraley JK, Rozelle JC, Brown FR Heird WC 2002 Relationship between omega3 long-chain polyunsaturated fatty acid status during early infancy and neurodevelopmental status at 1 year of age. J Hum Nutr Diet 15:111-120 